\title{
Use of carboxyhaemoglobin levels to predict the development of diseases associated with cigarette smoking
}

\author{
N I CHOLAS WALD ${ }^{1}$, SUSA N N A H OWAR D ${ }^{1}$, \\ P. G. S M I T H ${ }^{1}$, a n d A L A B A I L E Y ${ }^{2}$
}

DHSS Cancer Epidemiology and Clinical Trials Unit, Department of the Regius Professor of Medicine, Radcliffe Infirmary, Oxford $O X 26 H E^{1}$ and The BUPA Medical Centre, 210 Pentonville Road, London N1 9 T $A^{2}$

\begin{abstract}
Wald, N., Howard, Susannah, Smith, P. G., and Bailey, A. (1975). Thorax, 30, 133-140. Use of carboxyhaemoglobin levels to predict the development of diseases associated with cigarette smoking. Carboxyhaemoglobin $(\mathrm{COHb})$ levels in tobacco smokers vary throughout the day since they are affected by the pattern of tobacco consumption and the rate at which $\mathrm{COHb}$ is eliminated. A method is described whereby a single $\mathrm{COHb}$ measurement together with a recent smoking history may be used to estimate the average $\mathrm{COHb}$ 'boost' produced by each cigarette, the total daily carbon monoxide (CO) uptake from smoking, and the mean $\mathrm{COHb}$ level throughout the day. These three indices of tobacco smoke absorption were estimated in nine healthy cigarette smokers on different days, each set of three estimations being derived from separate COHb determinations. The indices were reasonably reproducible within the same person, and the differences between people were statistically highly significant $(P<0.001)$. For example, the estimates of mean daily $\mathrm{COHb}$ level resulting from smoking ranged from $0.7 \%$ to $9.3 \%$ in smokers who smoked 15 to 40 cigarettes a day. These differences are sufficiently large to distinguish possible differences in the risk of developing diseases such as ischaemic heart disease which may result from the inhalation and absorption of tobacco smoke. The suggested indices also depend less on the time of the blood test and on the daily pattern of smoking than a COHb level alone. The ratio of the $\mathrm{COHb}$ boost to the $\mathrm{CO}$ yield of a cigarette may reflect depth of inhalation more accurately than a smoker's self-assessment. Moreover there was little correlation between these two measures of inhalation in the nine subjects studied.
\end{abstract}

Men aged 40-49 years who smoke 20 cigarettes per day are about 10 to 15 times more likely to die of lung cancer and about three times more likely to die of ischaemic heart disease than nonsmokers (Doll and Hill, 1964; Hammond, 1971). The likely reason for this difference in relative risk is that smoking is the main cause of lung cancer while other factors such as hypertension and serum cholesterol level influence the risk of developing ischaemic heart disease (Kannel et al., 1961; Kannel et al., 1971). What is perhaps more puzzling is that some individuals smoke 20 cigarettes per day throughout their lives with little apparent ill effect. Some of the difference in the risk of developing these diseases among such smokers may be genetically determined
(Deutscher, Ostrander, and Epstein, 1970; Kellermann, Shaw, and Luyten-Kellerman, 1973), but the degree to which tobacco smoke is inhaled and absorbed is also likely to be important. In some studies information has been collected on self-reported inhalation habits, but the results of such studies have been conflicting (Doll and Hill, 1964; Hammond, 1966). A smoker's own assessment of inhalation may be unreliable and the situation might be clarified if more refined measures of inhalation and absorption of tobacco smoke were used.

Carbon monoxide (CO) is present in tobacco smoke and is inhaled to form carboxyhaemoglobin $(\mathrm{COHb})$. Although a relationship has been demonstrated between $\mathrm{COHb}$ levels and the 
prevalence of ischaemic heart disease (Wald et al., 1973), a single measurement of $\mathrm{COHb}$ probably does not adequately reflect a smoker's exposure to $\mathrm{CO}$ since the $\mathrm{COHb}$ level at any time is affected not only by the amount of $\mathrm{CO}$ absorbed from each cigarette but also by the pattern of recent tobacco consumption and by the rate at which $\mathrm{CO}$ is eliminated. The purpose of this paper is to show how a single measurement of $\mathrm{COHb}$, together with details of the subject's recent smoking history and level of activity, can be used to estimate the amount of $\mathrm{CO}$ absorbed from each cigarette, and thus the total $\mathrm{CO}$ absorbed each day and the mean daily $\mathrm{COHb}$ level.

\section{THEORY}

In this paper the $\mathrm{COHb}$ derived from the $\mathrm{CO}$ absorbed from each cigarette smoked is referred to as the 'COHb boost'. The size of this boost depends on various factors, such as the brand of cigarette smoked, the depth of inhalation, and the number of puffs per cigarette. We have assumed that, in a particular smoker, the boost produced by each cigarette smoked during the day is identical. After smoking a cigarette, the rate of elimination of $\mathrm{CO}$ from the blood is principally determined by the ventilation rate and the pulmonary transfer factor for CO. Figure 1, constructed from data given by Coburn, Forster, and Kane (1965), demonstrates the relationship between $\mathrm{COHb}$ half-life, alveolar ventilation, and activity. We have measured the half-life of $\mathrm{COHb}$ for four sedentary and five moderately active cigarette smokers. These smokers were asked to stop smoking for one hour, and venous blood samples were taken immediately and one hour later. The mean $\mathrm{COHb}$ half-life in the sedentary subjects was $2 \cdot 3$ hours (range $1 \cdot 3-3 \cdot 4$ ) and in moderately active subjects was $1 \cdot 1$ hours (range 0.6-1.3) (Wilcoxon test $P<0.01$ ). These values are in reasonable agreement with Fig. 1 and other data (Ashton and Telford, 1973; Russell et al., 1973). From this Figure it may be noted that at low levels of activity the rate of decay increases considerably for relatively small increases in activity.

The contribution of the $\mathrm{COHb}$ boost per cigarette to a smoker's $\mathrm{COHb}$ level decreases exponentially with the time since the cigarette was smoked, the half-life depending on the smoker's activity. Each cigarette may, thus, be considered separately and, at any time during the day, the excess of the COHb level above 'background' may be considered to be the sum of the

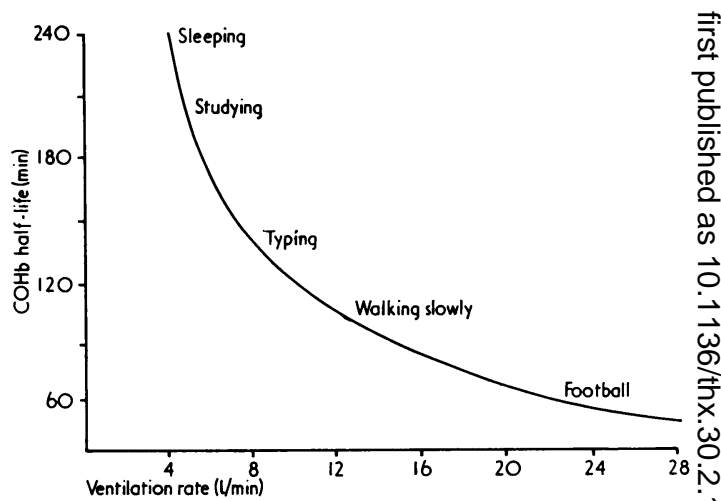

FIG. 1. Half-life of $\mathrm{COHb}$ in relation to alveolar $\vec{\omega}$ ventilation rate: produced from data published by Coburn et al. (1965). Adjustment has been made for the increase in transfer factor for $\mathrm{CO}$ with activity $\vec{\rightarrow}$ taking a value from $30 \mathrm{ml} \mathrm{min}^{-1} \mathrm{mg}^{-1}$ at rest to $50 \mathrm{ml} \mathrm{min}^{-1} \mathrm{mg}^{-1}$ with strenuous exercise such a football. The energy expenditure for each activity $\overrightarrow{\mathrm{b}}$ shown was taken from Passmore and Durnin (1955) and converted into alveolar ventilation rates using $3.45 \mathrm{ml}$ oxygen per calorie (Boothby, Berkson, and Dunn, 1936), a respiratory quotient of 0.82, and mean alveolar $\mathrm{CO}_{2}$ concentration of $5.6 \%$. It ha. been assumed that the inspired air contains no $C O$.

residual $\mathrm{COHb}$ boosts from each cigarette, each $\overrightarrow{5}$ of which has been decaying at a rate correspond 3 ing to the subject's activity in the intervening period. The 'background' level due to endogenous $\mathrm{CO}$ production and atmospheric exposure may be taken as the average $\mathrm{COHb}$ level in several non을 smokers working in the same environment as the smokers. In practice this figure rarely exceed $2.5 \%$ (Lawther and Commins, 1970).

Thus, if a smoking history is taken of the timê at which each cigarette was smoked in the pre ceding 24 hours, the contribution of each cigarette to the $\mathrm{COHb}$ in the blood sample can be con $\rightarrow$ sidered in terms of the 'COHb boost' and then the 'COHb boost' itself calculated from the measured COHb level (see Appendix). The smoking history need cover only the 24 hours before blood is taken for the $\mathrm{COHb}$ measurement, as the contribution to the $\mathrm{COHb}$ level from cigarettes smoked more than a day before the test is negligible.

\section{METHOD}

Venous blood samples from nine healthy cigarett ${ }^{7}$ smokers who worked at the BUPA Medical Centr were analysed for $\mathrm{COHb}$ using an IL $182{ }^{\circ} \mathrm{CO} \stackrel{\mathrm{D}}{\mathrm{D}}$ Oximeter'. Results obtained by this method were checked against the method of Commins an 
Lawther (1965), and all estimations were performed using two aliquots of each blood sample. The COHb level was taken as the average of the estimations from the two aliquots which, in general, were within $0.2 \%$ of each other. Each subject had samples taken in the afternoon on between two and eight different days. The subjects had not been asked to alter their normal smoking habits. Each time a blood sample was taken a questionnaire was completed on the time of waking, the time that each cigarette was smoked on the day of the test, the number of cigarettes smoked in each two-hour period of the previous day, and the time of going to sleep. The brand of cigarette smoked, the usual number smoked per day, and the subject's estimate of his normal depth of inhalation (nil, slight, moderate, or deep) were also recorded. They were not asked to keep a running record of the number of cigarettes smoked and were not informed of the experiment until the day of the test. The $\mathrm{CO}$ yield of each brand of cigarette smoked was determined using a smoking machine under standard conditions (Tobacco Research Council, 1972).

Similar data were later collected from six of the subjects on three separate mornings shortly after they had arrived at work. Again they were not asked to alter their normal smoking habits.

The level of activity of each subject during the 24 hours preceding the blood test was classified as sedentary (e.g., typing at a desk with little movement from the desk), light activity (e.g., typing with frequent departures from the desk), and moderately active (continuous walking about). Using Fig. 1, the $\mathrm{COHb}$ half-lives corresponding to these levels of activity were taken as $2 \frac{1}{2}$ hours, 2 hours, and 1 hour respectively. The $\mathrm{COHb}$ half-life during sleep was taken as 4 hours. The usual level of activity was recorded in the same categories. None of the subjects was involved in heavy manual work.

\section{RESULTS}

Details of the nine healthy subjects and the CO yields of the brands of cigarette they smoked are shown in Table I. The difference in CO yields between the various brands tested are significantly different $(F$ ratio $(8,12 \mathrm{df})=19.1 ; P<0.001)$, the estimate of the within-brand variance being $0.9 \mathrm{ml}^{2}$. Table II shows the mean values for the nine subjects of the following five indices of tobacco smoke absorption:

(i) usual number of cigarettes smoked each day;

(ii) $\mathrm{COHb}$ level at the time the blood sample was taken;

(iii) estimated $\mathrm{COHb}$ boost per cigarette, assuming exponential decay of $\mathrm{COHb}$ with a half-life of 4 hours while asleep and of $2 \frac{1}{2}$ hours, 2 hours, and 1 hour during the day, depending on level of activity on the day of the test;

(iv) estimated total daily $\mathrm{CO}$ uptake expressed in $\mathrm{COHb} \%$, i.e., the product of indices (i) and (iii);

(v) estimated mean $\mathrm{COHb}$ level above 'background' over 24 hours, derived from the total CO uptake (iv) in conjunction with an estimate of the subject's usual $\mathrm{COHb}$ daytime half-life, made on the basis of his normal activity.

(The indices which are computed from a $\mathrm{COHb}$ measurement were based upon blood samples taken in the afternoon.)

Table II also shows the ranks for each index. Variance ratio $(F)$ tests indicate that, for each of these indices, the differences between subjects are highly significant. Figure 2 shows the $\mathrm{COHb}$

T A B L E I

DETAILS OF SUBJECTS AND CO YIELDS OF THE BRANDS OF CIGARETTES THEY SMOKE

\begin{tabular}{|c|c|c|c|c|c|c|c|c|}
\hline \multirow[b]{2}{*}{ Subject } & \multirow[b]{2}{*}{ Age } & \multirow[b]{2}{*}{ Sex } & \multirow[b]{2}{*}{$\begin{array}{c}\text { Normal } \\
\text { Activity } \\
\text { Level }\end{array}$} & \multirow{2}{*}{$\begin{array}{c}\text { Usual } \\
\text { Number of } \\
\text { Cigarettes } \\
\text { Smoked } \\
\text { per day }\end{array}$} & \multirow[b]{2}{*}{$\begin{array}{l}\text { Brand of } \\
\text { Cigarette smoked } \\
\text { (all filter tipped) }\end{array}$} & \multicolumn{3}{|c|}{$\begin{array}{l}\text { CO Yield of Cigarette Smoked under } \\
\text { Standard Conditions (ml) }\end{array}$} \\
\hline & & & & & & $\begin{array}{c}\text { No. of } \\
\text { Cigarettes } \\
\text { tested }\end{array}$ & Mean & Range \\
\hline $\begin{array}{l}\text { PH } \\
\text { DR } \\
\text { HM } \\
\text { VT } \\
\text { MS } \\
\text { BC } \\
\text { AH } \\
\text { LS } \\
\text { ES }\end{array}$ & $\begin{array}{l}44 \\
38 \\
19 \\
30 \\
30 \\
33 \\
27 \\
24 \\
52\end{array}$ & $\begin{array}{l}\mathbf{F} \\
\mathbf{M} \\
\mathbf{F} \\
\mathbf{F} \\
\mathbf{M} \\
\mathbf{F} \\
\mathbf{F} \\
\mathbf{F}\end{array}$ & $\begin{array}{l}\mathbf{L} \\
\mathbf{S} \\
\mathbf{M} \\
\mathbf{M} \\
\mathbf{L} \\
\mathbf{M} \\
\mathbf{M} \\
\mathbf{S} \\
\mathbf{S}\end{array}$ & $\begin{array}{l}40 \\
25 \\
20 \\
25 \\
25 \\
20 \\
15 \\
20 \\
15\end{array}$ & $\begin{array}{l}\text { Rothmans King Size } \\
\text { Players No. 6 King Size } \\
\text { John Player Special } \\
\text { Consulate (Menthol) } \\
\text { Gitanes Caporal } \\
\text { Peter Stuyvesant King Size } \\
\text { Embassy Extra Mild } \\
\text { Dunhill International } \\
\text { Piccadilly King Size }\end{array}$ & $\begin{array}{l}2 \\
2 \\
2 \\
3 \\
2 \\
3 \\
2 \\
2 \\
3\end{array}$ & $\begin{array}{r}17 \cdot 6 \\
17 \cdot 8 \\
16 \cdot 5 \\
15 \cdot 4 \\
14 \cdot 4 \\
12 \cdot 9 \\
9 \cdot 2 \\
16 \cdot 0 \\
17 \cdot 8\end{array}$ & $\begin{array}{l}17 \cdot 1-18 \cdot 1 \\
17 \cdot 2-18 \cdot 4 \\
16 \cdot 0-17 \cdot 0 \\
14 \cdot 1-16 \cdot 5 \\
14 \cdot 1-14 \cdot 8 \\
11 \cdot 3-14 \cdot 4 \\
8 \cdot 6-9 \cdot 9 \\
15 \cdot 7-16 \cdot 2 \\
17 \cdot 6-18 \cdot 1\end{array}$ \\
\hline
\end{tabular}

$\mathbf{S}=$ Sedentary.

$\mathbf{L}=$ light activity

$\mathbf{M}=$ moderate activity. 
T A B L E I I

COMPARISON OF INDICES OF TOBACCO SMOKE ABSORPTION

\begin{tabular}{|c|c|c|c|c|c|c|}
\hline Subject & $\begin{array}{c}\text { No. } \\
\text { of Tests }\end{array}$ & $\begin{array}{c}\text { (i) } \\
\text { Average No. } \\
\text { of Cigarettes } \\
\text { smoked per Day }\end{array}$ & $\begin{array}{c}\text { (ii) } \\
\text { pm } \\
\text { coHb Level } \\
\%\end{array}$ & $\begin{array}{l}\text { (iii) } \\
\text { COHb Boost per } \\
\text { Cigarette, allow- } \\
\text { ing for Activity } \\
\text { on Day of Test }{ }^{1} \\
\% \\
\%\end{array}$ & $\begin{array}{c}\text { (iv) } \\
\text { Total Daily } \\
\text { CO Uptake } \\
\% \text { COHb }\end{array}$ & $\begin{array}{l}\text { (v) } \\
\text { Daily Mean } \\
\text { COHb Level } \\
\text { above Back- } \\
\text { ground allowing } \\
\text { for Normal } \\
\text { Activity } \\
\% \\
\%\end{array}$ \\
\hline $\begin{array}{l}\text { PH } \\
\text { DR } \\
\text { HM } \\
\text { VT } \\
\text { MS } \\
\text { BC } \\
\text { AH } \\
\text { LS } \\
\text { ES }\end{array}$ & $\begin{array}{l}5 \\
6 \\
5 \\
5 \\
4 \\
8 \\
2 \\
4 \\
4\end{array}$ & $\begin{array}{l}40(1) \\
25(3) \\
20(6) \\
25(3) \\
25(3) \\
20(6) \\
15(8 \cdot 5) \\
20(6) \\
15(8 \cdot 5)\end{array}$ & $\begin{array}{c}14.7 \pm 1 \cdot 1 \text { (1) } \\
8.6 \pm 1.8(2) \\
5.2 \pm 1 \cdot 3 \text { (5) } \\
5.2 \pm 1 \cdot 1 \text { (6) } \\
6.9 \pm 0.9 \text { (3) } \\
4.4 \pm 1.0(8) \\
5.8 \pm 0.1 \text { (4) } \\
5.0 \pm 0.9 \text { (7) } \\
2.8 \pm 0.6(9)\end{array}$ & $\begin{array}{l}1.9 \pm 0.1 \text { (5) } \\
1.2 \pm 0.4(6) \\
3.3 \pm 1.0(1) \\
2.6 \pm 0.9(2) \\
1.2 \pm 0.3(7) \\
2.1 \pm 0.5(4) \\
2.5 \pm 1.5(3) \\
0.7 \pm 0.1 \text { (8) } \\
0.3 \pm 0.2(9)\end{array}$ & $\begin{array}{l}74 \pm 5(1) \\
31 \pm 10(6) \\
67 \pm 19(2) \\
65 \pm 24(3) \\
30 \pm 6(7) \\
41 \pm 10(4) \\
37 \pm 22(5) \\
14 \pm 3(8) \\
5 \pm 3(9)\end{array}$ & $\begin{array}{l}9.3 \pm 0.7(1) \\
4.6 \pm 1.6(2) \\
4.5 \pm 1.3(3) \\
4.4 \pm 1.6(4) \\
3.8 \pm 0.8(5) \\
2.8 \pm 0.6(6) \\
2.5 \pm 1.5(7) \\
2.2 \pm 0.4(8) \\
0.7 \pm 0.5(9)\end{array}$ \\
\hline $\begin{array}{c}\text { F ratio } \\
(\mathbf{8}, 34 \text { df })\end{array}$ & & & $49 \cdot 3^{2}$ & $11 \cdot 6^{2}$ & $16 \cdot 5^{2}$ & $26 \cdot 8^{2}$ \\
\hline
\end{tabular}

The values given in columns (ii) to (v) are the means of individual estimates of each index \pm SD.

The ranks are shown in parentheses.

Sedentary: half-life $2 \mathrm{th}$.

Light activity: half-life $2 \mathrm{~h}$.

Moderate activity: half-life $1 \mathrm{~h}$.
$2 \mathrm{P}<0.001$.

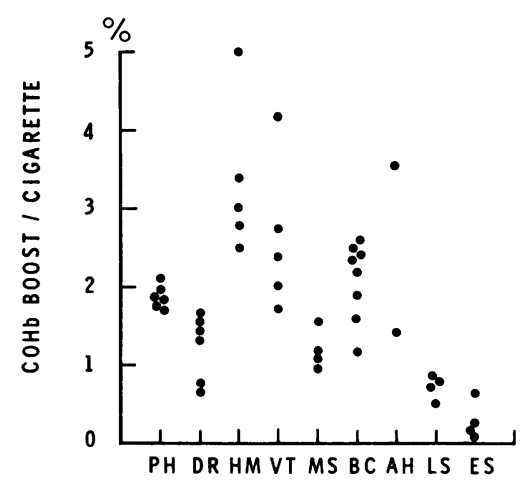

FIG. 2. Estimated $\mathrm{COHb}$ boost per cigarette. Each point represents the estimated value based on a single $\mathrm{COHb}$ measurement, the smoking history in the preceding 24 hours, and the level of activity on the day of the test.

boost per cigarette (as in (iii) above) estimated from blood samples and smoking questionnaires from the same subjects on different days. Figure 3 shows, in a similar way, the estimated mean $\mathrm{COHb}$ levels. Although there is day-to-day variability, some subjects are consistently different from others.

Table III shows the mean $\mathrm{COHb}$ levels and the mean estimates of the $\mathrm{COHb}$ boost per cigarette based on data collected from six of the subjects in the morning. Data were not obtained from three of the subjects because they had either left the Medical Centre or had stopped smoking. The $\mathrm{COHb}$ levels in the afternoon are, on average, double those obtained in the morning, whereas the estimates of $\mathrm{COHb}$ boost per cigarette basedo on afternoon $\mathrm{COHb}$ levels are, on average, onlys 0.9 times the morning estimates. These data sug gest that $\mathrm{COHb}$ levels in the morning may under $\frac{\mathrm{O}}{\mathrm{D}}$ estimate a person's exposure to $\mathrm{CO}$, but that the



FIG. 3. Estimated mean daily $\mathrm{COHb}$ levels above 'background'. Each point represents the estimated value based on a single estimate of $\mathrm{COHb}$ boost pe $\overrightarrow{\mathrm{R}}$ cigarette, the usual daily cigarette consumption, and
the usual level of activity. 


\section{T A B L E I I I}

COMPARISON OF COHb LEVELS AND COHb BOOST PER CIGARETTE BASED ON BLOOD SAMPLES TAKEN IN MORNING AND AFTERNOON

\begin{tabular}{|c|c|c|c|c|c|}
\hline Subject & $\begin{array}{l}\text { No. } \\
\text { of Tests }\end{array}$ & $\underset{\text { am COHb } \%}{\text { Mean }}$ & $\begin{array}{c}\text { Mean COHb } \\
\text { Boost per Cigarette } \\
\text { based on am COHb \% }\end{array}$ & $\begin{array}{l}\text { Ratio of Mean } \\
\text { pm COHb\% to } \\
\text { Mean am COHb \% }\end{array}$ & $\begin{array}{c}\text { Ratio of Mean } \\
\text { pm COHb Boost to } \\
\text { Mean am COHb Boost }\end{array}$ \\
\hline $\begin{array}{l}\text { PH } \\
\text { DR } \\
\text { HM } \\
\text { MS } \\
\text { BC } \\
\text { LS }\end{array}$ & $\begin{array}{l}\mathbf{3} \\
\mathbf{3} \\
\mathbf{3} \\
\mathbf{3} \\
\mathbf{3} \\
\mathbf{3}\end{array}$ & $\begin{array}{l}6 \cdot 8 \\
5 \cdot 1 \\
2 \cdot 2 \\
2 \cdot 9 \\
2 \cdot 2 \\
3 \cdot 9\end{array}$ & $\begin{array}{l}2.8 \\
1.2 \\
1.9 \\
1.9 \\
2.1 \\
1.3\end{array}$ & $\begin{array}{l}2 \cdot 2 \\
1 \cdot 7 \\
2 \cdot 4 \\
2 \cdot 4 \\
2 \cdot 0 \\
1 \cdot 3\end{array}$ & $\begin{array}{l}0.7 \\
1.0 \\
1.7 \\
0.6 \\
1.0 \\
0.5\end{array}$ \\
\hline \multicolumn{4}{|r|}{ Geometric mean } & $2 \cdot 0$ & 0.9 \\
\hline
\end{tabular}

estimates of $\mathrm{COHb}$ boost per cigarette are relatively independent of the time of taking blood. The estimates of the total daily $\mathrm{CO}$ uptake and the mean daily $\mathrm{COHb}$ level, which are derived from the $\mathrm{COHb}$ boost per cigarette, are therefore also less dependent on the time of taking blood than the COHb level alone.

Table IV shows, for each subject, the ratio of the $\mathrm{COHb}$ boost per cigarette to the $\mathrm{CO}$ yield of their brand of cigarette and the self-assessed inhalation rating.

T A B L E I V

SELF-REPORTED INHALATION HABITS AND RATIO OF COHb BOOST TO CO YIELD OF CIGARETTES SMOKED

\begin{tabular}{c|c|c}
\hline Subject & $\begin{array}{c}\text { Self-assessed } \\
\text { Inhalation Rating } \\
\text { (A=nil; B=- slight; } \\
\text { C=moderate; D=deep) }\end{array}$ & $\begin{array}{c}\text { COHb Boost/CO Yield } \\
\text { of Cigarette } \\
(\% \text { ml-1) }\end{array}$ \\
\hline PH & C & $0 \cdot 11$ \\
DR & D & $0 \cdot 07$ \\
HM & C & $0 \cdot 20$ \\
VT & C & $0 \cdot 17$ \\
MS & D & $0 \cdot 08$ \\
BC & B & $0 \cdot 16$ \\
AS & B & $0 \cdot 27$ \\
ES & C & $0 \cdot 04$ \\
\hline
\end{tabular}

\section{DISCUSSION}

$\mathrm{COHb}$ levels vary throughout the day since they are affected by the pattern of recent tobacco consumption and the rate at which $\mathrm{CO}$ is eliminated. The importance of the pattern of smoking is illustrated by Fig. 4 which shows the $\mathrm{COHb}$ levels during a 24-hour period for two hypothetical cigarette smokers, A who smokes mainly in the evening and B who smokes steadily throughout the day. Both $A$ and B smoke 20 cigarettes per day, inhale to the same extent (that is, have the same boost per cigarette), and eliminate $\mathrm{CO}$ at the same rate. $\mathrm{A}$ and $\mathrm{B}$ have the same exposure to tobacco smoke, but only at 0900 hours and 1900 hours are their $\mathrm{COHb}$ levels

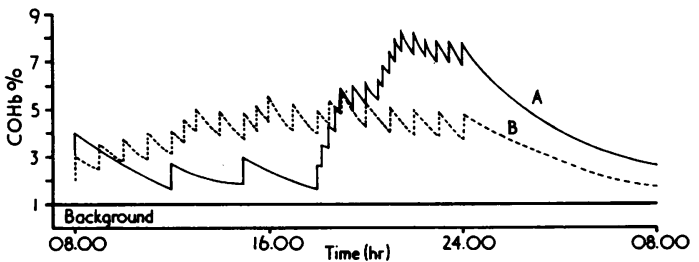

FIG. 4. Examples of $\mathrm{COHb}$ patterns in two smokers. Each smokes 20 cigarettes daily but at different times. They both eliminate $\mathrm{COHb}$ at the same rate (halflife of 4 hours while asleep from 0000 to 0800 hours and $a$ half-life of 2 hours while awake from 0800 to 2400 hours). Vertical lines represent the increase in $\mathrm{COHb}$ level produced by each cigarette; this $\mathrm{COHb}$ 'boost' has been taken as $1 \% \mathrm{COHb}$ per cigarette for both smokcrs. For simplicity, each cigarette has been shown to have been smoked instantaneously. The 'background' $\mathrm{COHb}$ level due to endogenous $\mathrm{CO}$ production and atmospheric $\mathrm{CO}$ exposure has been taken as $1 \%$.

the same, and blood samples at other times will not reflect their exposure to tobacco smoke throughout the day. In this paper we have attempted to derive measures of exposure to $\mathrm{CO}$ which do not require multiple blood samples but which take into account variability in $\mathrm{COHb}$ values due to a person's recent smoking history and level of activity. While we have not formally validated the accuracy of the recent smoking history, subjects were reasonably confident that information relating to smoking on the day of the blood test (the day the questionnaire was completed) was correct. They were less confident about such information relating to the previous day, but since the residual $\mathrm{COHb}$ from that day is very small in comparison with that produced on the day of the test, any associated error is unlikely to be important.

The method of estimating $\mathrm{COHb}$ per cigarette that we propose computes an average of the boosts from each individual cigarette. It has been 
assumed that the boost produced by a cigarette is not dependent upon the $\mathrm{COHb}$ level at the time of starting to smoke the cigarette. This assumption may not be completely justified but the variation in boost that such an effect might produce is likely to be small compared with the 'random' variation in boost from cigarette to cigarette, such as from varying the number of puffs per cigarette. It is also likely that any dependence of boost on $\mathrm{COHb}$ level will vary from person to person. We therefore consider it reasonable to assume a constant boost for each cigarette.

The $\mathrm{COHb}$ boost per cigarette will depend on the method of smoking (the size and number of puffs and the depth of inhalation), the pulmonary transfer factor, and the $\mathrm{CO}$ yield from the cigarette. The between-person variation in transfer factor is about twofold (Filley, MacIntosh, and Wright, 1954), and apart from Embassy Extra Mild the between-brand variation in $\mathrm{CO}$ yield of cigarettes smoked in this study is even smaller (Table I). Cigarettes such as Embassy Extra Mild which have perforated filter tips have low $\mathrm{CO}$ yields, but they are also unusual in several other respects and there is evidence that smoking such cigarettes may result in deeper inhalation of the smoke (Wald and Smith, 1973). The betweenperson variation in $\mathrm{COHb}$ boost per cigarette is at least tenfold (Fig. 3). This indicates that the method of smoking is the main factor affecting $\mathrm{COHb}$ boost per cigarette, although from the data collected in this study it is not possible to isolate the independent effects of size of puff, number of puffs, or depth of inhalation. This is probably not of practical importance since a disease resulting from smoking is likely to be associated with all three factors. The ratio of the $\mathrm{COHb}$ boost per cigarette to the $\mathrm{CO}$ yield of the cigarette provides an objective measure of these factors combined. As shown in Table IV, this ratio does not correlate with a person's opinion of his depth of inhalation and this may account for some of the conflicting results of studies using self-reported inhalation habits. In this study the $\mathrm{CO}$ yield of cigarettes was determined under standard laboratory conditions and while the results are likely to reflect the actual $\mathrm{CO}$ yield, when these cigarettes are smoked normally the yields will not always be the same as the laboratory results. The COHb boost per cigarette will also depend on a person's total haemoglobin and myoglobin content. In general, these are relatively unimportant determinants of $\mathrm{COHb}$ levels, and they have not been considered in our calcula- tions. The COHb boost per cigarette is also likely to decrease with age and with the development $\stackrel{\vec{P}}{+}$ of lung disease although there will also be a compensatory decrease in the rate of elimination of $\mathrm{COHb}$.

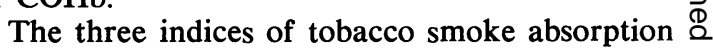
shown in Table II, COHb boost, CO uptake, and क mean daily $\mathrm{COHb}$ level, are all reasonably repro- $\overrightarrow{0}$ ducible within the same subject and are sufficiently different between groups of subjects to $\vec{\omega}$ distinguish possible differences in risk. A comparison of columns (iv) and (v) shows the results $\vec{x}$ of allowing for usual activity levels; for example, $\omega$ subject DR is apparently at fairly low risk accord- î ing to his CO uptake, but as he is normally $\vec{\omega}$ sedentary his $\mathrm{COHb}$ during the day is high. Tables $\omega$ II and III suggest that there is greater random 을 variation in these indices than in the $\mathrm{COHb} \rightarrow$ measurements themselves. However, the indices $\frac{7}{0}$ are, on average, independent of the time of taking blood whereas the $\mathrm{COHb}$ levels are not.

It is not possible to say which of the measures of of risk we have discussed will correlate best with the incidence of disease in a prospective study, or indeed if any of them are better than simply the amount smoked. It is likely that the 'best' measure would be different for different diseases. Cholesterol deposition into the aorta of a rabbit is greater as a result of intermittent $\mathrm{CO}$ administration than with continuous exposure, even though the rate of administration is the same in both cases (Astrup, 1972), and thus a further possible predictor of disease is the 'peak' $\mathrm{COHb}$ value during the day. We have not calculated this value in cur subjects, but if data are collected in the way we have described this could easily be done.

$\mathrm{CO}$ is only one of many constituents of tobacco smoke but the absorption of other constituents in the smoke might be related to the $\mathrm{CO}$ uptake. This is likely to be the case for other constituents which, like $\mathrm{CO}$, are absorbed through the lungs, although the precise extent of the absorption $N$ may depend on other factors such as the pH of $N$ the smoke. In a particular brand of cigarette, by N relating the $\mathrm{CO}$ yield to that of another con- $\omega$ stituent, the pulmonary intake of this other constituent can be estimated. If $\mathrm{CO}$ is itself $\stackrel{\circ}{\mathrm{O}}$

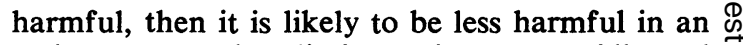
active person who eliminates it more rapidly and has a lower mean $\mathrm{COHb}$ level, whereas the effect of other harmful constituents which may not be $\overrightarrow{\mathbb{D}}$

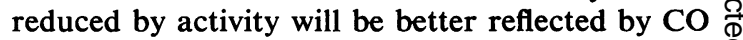
uptake, or better still by the ratio of $\mathrm{COHb}$ boost to $\mathrm{CO}$ yield of a cigarette times the number of 
cigarettes smoked each day. Indeed, if in a prospective study the incidence of ischaemic heart disease were found to be more closely related to the mean $\mathrm{COHb}$ level than to the $\mathrm{CO}$ uptake, this would support the claim that $\mathrm{CO}$ was a cause of this disease.

We thank Ann Pollard and Paul Humphreys for technical assistance and the staff of the BUPA Medical Centre who kindly agreed to be subjects in the experiments. We thank John Evans of the National Coal Board, Edinburgh, for determining the $\mathrm{CO}$ yields of the cigarette brands smoked by the subjects. We also thank Sir Richard Doll, Dr. R. Marshall, Dr. D. Mason, and Professor M. P. Vessey for their helpful advice.

\section{REFERENCES}

Ashton, H. and Telford, R. (1973). Blood carboxyhaemoglobin levels in smokers. British Medical Journal, 4, 740.

Astrup, P. (1972). Some physiological and pathological effects of moderate carbon monoxide exposure. British Medical Journal, 4, 447.

Boothy, W. M., Berkson, J., and Dunn, H. L. (1936). Studies of the energy of metabolism of normal individuals: a standard for basal metabolism, with a nomogram for clinical application. American Journal of Physiology, 116, 468.

Coburn, R. F., Forster, R. E., and Kane, P. B. (1965). Considerations of the physiological variables that determine the blood carboxyhemoglobin concentration in man. Journal of Clinical Investigation, 44, 1899.

Commins, B. T. and Lawther, P. J. (1965). A sensitive method for the determination of carboxyhaemoglobin in a finger prick sample of blood. British Journal of Industrial Medicine, 22, 139.

Deutscher, S., Ostrander, L. D., and Epstein, F. H. (1970). Familial factors in premature coronary heart disease-a preliminary report from the Tecumseh Community Health Study. American Journal of Epidemiology, 91, 233.

Doll, R. and Hill, A. B. (1964). Mortality in relation to smoking: ten years' observations of British doctors. British Medical Journal, 1, 1399.

Filley, G. F., MacIntosh, D. J., and Wright, G. W. (1954). Carbon monoxide uptake and pulmonary diffusing capacity in normal subjects at rest and during exercise. Journal of Clinical Investigation, 33, 530 .
Hammond, E. C. (1966). Smoking in relation to the death rates of one million men and women. In: Epidemiological Approaches to the Study of Cancer and Other Chronic Diseases, p. 127, edited by W. Haenszel. National Cancer Institute Monograph 19, National Cancer Institute, Bethesda, Maryland.

(1971). Smoking in relation to diseases other than cancer. Total death rates. In: Proceedings of the Second World Conference on Smoking and Health, edited by R. G. Richardson, p. 24. Pitman, London.

Kannel, W. B., Castelli, W. P., Gordon, T., and McNamara, P. M. (1971). Serum cholesterol, lipoproteins, and the risk of coronary heart disease. Annals of Internal Medicine, 74, 1.

, Dawber, T. R., Kagan, A., Revotskie, N., and Stokes, J. (1961). Factors of risk in the development of coronary heart disease-six-year followup experience. Annals of Internal Medicine, 55, 33.

Kellermann, G., Shaw, C. R., and Luyten-Kellerman, M. (1973). Aryl hydrocarbon hydroxylase inducibility and bronchogenic carcinoma. New England Journal of Medicine, 289, 934.

Lawther, P. J., and Commins, B. T. (1970). Cigarette smoking and exposure to carbon monoxide. Annals of the New York Academy of Science, 174, 135.

Passmore, R. and Durnin, J. V. G. A. (1955). Human energy expenditure. Physiological Reviews, 35, 801 .

Russell, M. A. H., Wilson, C., Patel, U. A., Cole, P. V., and Feyerabend, C. (1973). Comparison of effect on tobacco consumption and carbon monoxide absorption of changing to high and low nicotine cigarettes. British Medical Journal, 4, 512.

Tobacco Research Council (1972). Standard methods for the analysis of tobacco smoke. Research Paper No. 11, edited by K. Rothwell and C. A. Grant.

Wald, N., Howard, S., Smith, P. G., and Kjeldsen, K. (1973). Association between atherosclerotic diseases and carboxyhaemoglobin levels in tobacco smokers. British Medical Journal, 1, 761 .

and Smith, P. G. (1973). Smoking tables for carbon monoxide? Lancet, 2, 907.

Requests for reprints to: Dr. N. Wald, DHSS Cancer Epidemiology and Clinical Trials Unit, Department of the Regius Professor of Medicine, Radcliffe Infirmary, Oxford OX2 6HE. 


\section{APPENDIX}

HAND CALCULATION OF THE INDICES OF TOBACCO SMOKE ABSORPTION

(a) Decay factors

\begin{tabular}{|c|c|c|c|c|}
\hline \multirow[b]{2}{*}{$\begin{array}{c}\text { Time } \\
\text { elapsed } \\
\text { since } \\
\text { Smoking } \\
\text { Cigarette }\end{array}$} & \multicolumn{4}{|c|}{ Activity on Day of COHb Measurement } \\
\hline & $\begin{array}{l}\text { Sleeping } \\
\text { (half-life } \\
4 \text { hours) }\end{array}$ & $\begin{array}{r}\text { Sedentary } \\
\text { (half-life } \\
2 \frac{1}{2} \text { hours) }\end{array}$ & $\begin{array}{c}\text { Light } \\
\text { (half-life } \\
2 \text { hours) }\end{array}$ & $\begin{array}{c}\text { Moderate } \\
\text { (half-life } \\
1 \text { hour) }\end{array}$ \\
\hline $\begin{array}{c}15 \mathrm{~min} \\
30 \mathrm{~min} \\
45 \mathrm{~min} \\
1 \mathrm{~h} \\
1 \mathrm{~h} 30 \mathrm{~min} \\
2 \mathrm{~h} \\
3 \mathrm{~h} \\
4 \mathrm{~h} \\
5 \mathrm{~h} \\
6 \mathrm{~h} \\
7 \mathrm{~h} \\
8 \mathrm{~h} \\
9 \mathrm{~h} \\
10 \mathrm{~h} \\
11 \mathrm{~h} \\
12 \mathrm{~h}\end{array}$ & $\begin{array}{l}0.96 \\
0.92 \\
0.88 \\
0.84 \\
0.77 \\
0.71 \\
0.59 \\
0.50 \\
0.42 \\
0.35 \\
0.30 \\
0.25 \\
0.21 \\
0.18 \\
0.15 \\
0.13\end{array}$ & $\begin{array}{l}0.93 \\
0.87 \\
0.81 \\
0.76 \\
0.66 \\
0.57 \\
0.44 \\
0.33 \\
0.25 \\
0.19 \\
0.14 \\
0.11 \\
0.08 \\
0.06 \\
0.05 \\
0.04\end{array}$ & $\begin{array}{l}0.92 \\
0.84 \\
0.77 \\
0.71 \\
0.59 \\
0.50 \\
0.35 \\
0.25 \\
0.18 \\
0.13 \\
0.09 \\
0.06 \\
0.04 \\
0.03 \\
0.02 \\
0.02\end{array}$ & $\begin{array}{l}0.84 \\
0.71 \\
0.59 \\
0.50 \\
0.35 \\
0.25 \\
0.13 \\
0.06 \\
0.03 \\
0.02 \\
0.01 \\
0 \\
0 \\
0 \\
0 \\
0\end{array}$ \\
\hline
\end{tabular}

(b) Load factors ${ }^{1}$

\begin{tabular}{c|c|c}
\hline \multicolumn{2}{|c|}{ Normal Activity } \\
\cline { 2 - 2 } Sedentary & Light & Moderate \\
\hline 0.15 & 0.13 & 0.07 \\
\hline
\end{tabular}

${ }^{1}$ The load factor assumes an 8 -hr period of sleep and a constant rate of smoking during the day.
CALCULATION

(i) Mean COHb boost per cigarette

$=(\mathrm{COHb}$ level - non-smokers' background $\mathrm{COHb}$ level)

$$
\left(d_{1}+d_{2}+d_{i} \ldots .\right)
$$

where $d_{1}$ is decay factor for the most recent $\&^{\circ}$ cigarette smoked (read from table (a)), $d_{2}$ is $\overrightarrow{0}$ decay factor for the penultimate cigarette smoked, etc. Include at least the last five $\vec{\omega}$ cigarettes if possible. Cigarettes smoked the pre- $\stackrel{S}{\circ}$ vious day should be excluded unless the test is $\overrightarrow{\vec{x}}$ performed early in the morning before any cigarettes have been smoked, when the decay $O$ factor should be read from the 'sleeping' column.

(ii) Mean daily $\mathrm{CO}$ uptake $=$ average $\mathrm{COHb}$ boost per cigarette $\times$ average number of cigarettes smoked per day

(iii) Mean daily $\mathrm{COHb}$ level $=$ average daily $\mathrm{CO}$ uptake $\times$ load factor

The proposed indices of tobacco smoke absorption can be estimated by hand using the Appendix or by using a computer program. Copies of the program may be obtained from the authors. 